\title{
Leverage Effect and Switching of Market Efficiency Post Goods and Services Tax (GST) Imposition
}

\author{
Yok-Yong Lee ${ }^{1}$, M. H. Yahya ${ }^{2}$, A. N. Bany-Ariffin ${ }^{2} \&$ S. Aslam ${ }^{2}$ \\ ${ }^{1}$ Putra Business School, Universiti Putra Malaysia, Malaysia \\ ${ }^{2}$ Faculty of Economics and Management, Universiti Putra Malaysia, Malaysia \\ Correspondence: Yok-Yong Lee, Putra Business School, Universiti Putra Malaysia, Malaysia.
}

Received: January 12, 2018

Accepted: February 9, $2018 \quad$ Online Published: February 19, 2018

doi:10.5539/ibr.v11n3p162

URL: https://doi.org/10.5539/ibr.v11n3p162

\begin{abstract}
This paper investigates the leverage effect and switching of market efficiency after the GST imposition on fee-based financial services in Bursa Malaysia and Australian Securities Exchange (ASX). The sample in this paper comprises of public listed companies for the period of one year before and after the GST imposition. GJR-GARCH is employed to evaluate the asymmetry response that is associated with the negative news shocks. To assess the effect of transactional efficiency on the informational efficiency and the structural change of time-varying volatility, SGARCH is adopted. This research reveals the presence of leverage effect in developing and developed market. The GST imposition on fee-based financial services significantly reduces the informational efficiency in Bursa Malaysia, but not in ASX. To boost the tax revenues generated from the financial sector, the policymakers in the developed markets (similar to ASX) should contemplate imposing GST on the fee-based financial services without affecting the stability of the stock market. The investors in thin markets (such as Bursa Malaysia) could forecast the stock returns of the thin market upon GST imposition on fee-based financial services.
\end{abstract}

Keywords: Efficient Market Hypothesis (EMH), Financial Transaction Taxes (FTT), Goods and Services Tax (GST), leverage effect, market efficiency, GJR-GARCH, Switching Generalized Autoregressive Conditional Heteroscedasticity (SGARCH)

\section{Introduction}

Financial crises have occurred almost every decade. The recent financial crisis in 2007-2008 is widely regarded as among the most severe since the Great Depression. The financial transaction tax (FTT), which is also known as the Robin Hood Tax, has attracted renewed interest from governments in their efforts to ease the burdens due to financial crisis This has ignited heated debates amidst the policymakers and the researchers (Claessens, Keen \& Pazarbasioglu, 2010; Hayashida \& Ono, 2011; Pomeranets \& Weaver, 2011; Pomeranets, 2012; Burman et al., 2016). The idea underpinning for the Robin Hood Tax is that it is aimed at the rich. This, in turn, is used for (1) the benefit of the poor, (2) funding the future financial crisis and (3) reducing the sovereign debts (Burman et al., 2016). The FTT advocates stressed that, apart from generating substantial tax revenues to recoup the costs of the financial crisis, FTT imposition may (1) mitigate excessive stock market volatility by curtailing noise investors and abating speculation and (2) enhance the market efficiency (Stiglitz, 1989; Song \&Zhang, 2005; Baltagi, Li \& Li, 2006; Pomeranets \& Weaver, 2011; Capelle-Blancard \& Havrylchyk, 2014; Hvozdyk \& Rustanov, 2016). However, the FTT opponents dispute that the FTT imposition is like "throwing sands in the wheel of the financial markets" (Tobin, 1978), which results to problems, including, destabilizing the stock market volatility, hinder the stock market efficiency and drop in the stock trading volume (Grundfest \& Shoven, 1991; Schwert \& Seguin, 1993; Hakkio, 1994; Li, Tang, Shang \& Wang, 2013).

The effect of FTT imposition has frequently been reexamined, yet no consensus has been reached. FTT is an "answer in search of a question" (Cochrane, 2013). To raise the tax revenues without causing drawbacks in the stock markets, an alternative should be sought to tax on the financial markets. Alternatively, there are two ways to tax on the financial markets: (1) FTT or (2) Goods and Services Tax (GST), which is also known as a Value-Added Tax (VAT) (Correa, Lorca \& Parro, 2015). FTT could be regarded as an extension of GST to tax on the financial markets (Arellano \& Corbo, 2013). Therefore, it is worthwhile to contemplate the possibility to impose GST on the financial markets without producing significant friction in the stock markets. Despite the 
compromise on tax neutrality, consequences to a competitive distortion and diversion in tax-revenue, most countries that have implemented GST, exempt the financial services from GST. This is owing to (1) the difficulty in quantifying the "value-added" component of financial services on a transaction-by-transaction basis and (2) the financial services are ancillary to the acquisition and trading of goods and services (KPMG, 2013). Financial services often consist of money-against-money transactions. It can be complicated to distinguish between transaction and income. The accounting services provider's reports ease the measurement of "value-added" or consideration received by the service provider. However, quantifying the consideration on a transaction-by-transaction basis is not straightforward. There is no requirement for financial services provider to distinguish implicit fees from the financial margins. Moreover, financial services are supposed to make possible the purchase of goods or services, which is then followed by the GST imposition. Therefore, many countries exempt both explicit fees and implicit fees from GST imposition.

Nonetheless, Australia, Malaysia and South Africa have imposed GST on fee-based financial services (KPMG, 2013). Fee-based agency services, arrangement and facilitation services in connection with the actual financial supply are taxable in Australia (Stitt, 2011). Likewise, the fee-based financial services in relation to the providing of facilities, coordinating, broking, underwriting or advising are subjected to GST at a standard rate in Malaysia. Similarly, VAT provisions tax on the explicit fee-based financial services but is exempted from the margin-based financial services in South Africa (KPMG, 2013). Thus, Bursa Malaysia, Australian Securities Exchange (ASX) and Johannesburg Stock Exchange (JSE) provide appropriate stock market conditions to explore the effect of GST, which is relatively negligible transaction costs compare to FTT, on the stock market efficiency. In light of data constraint in JSE, this paper provides an empirical examination regarding the effect of GST imposition on the market efficiency in Bursa Malaysia and ASX.

The Efficient Market Hypothesis (EMH) theorises that in an "efficient" stock market, the stock prices always "fully reflect" all available information (Fama, 1970). The market efficiency and self-correcting ability of financial markets are imperative to circumvent the financial crisis (Katusiime, Shamsuddin \& Agbola, 2015). There are three sufficient conditions (albeit, not necessarily) to achieve an "efficient" market: (1) a frictionless stock market that does not contain transaction costs, (2) costless information is available to the investors, (3) homogeneous investors' expectations (Fama, 1970). Loosely speaking, these sufficient conditions are not necessary sources that give rise to the market inefficiency, but they are potential sources. Nevertheless, costless information available to the investors is redefined as a necessary condition (Grossman \& Stiglitz, 1980). In a frictionless market, with the absence of transaction costs, a weak form efficient market is still impossible due to irrational investors (Slezak, 2003). This paper provides new insights into the existing literature of irrational investors by investigating the asymmetry responses between positive and negative news shocks that attributable from the irrational investors.

Generally, market efficiency can be classified into three types: (1) informational efficiency (known as external efficiency), (2) transactional efficiency (regarded as operational or internal efficiency) and (3) allocational efficiency (West, 1975). Informational efficiency infers that stock prices fully reflect all available information under the condition that the stock market is imposed with an identical standard set of rules and cannot outperform each other with existing information. Despite the unattainability of a frictionless stock market (with the absence of transaction costs), transaction costs in relation to the financial services should be kept at a reasonable level, to avoid the creation of an obstacle towards informational efficiency. This is known as a transactional efficiency. A transactional efficiency signifies the speed that information is reflected in the stock prices after considering the stock market frictions. The stock market frictions exist in the form of transaction costs, trading halts, circuit-breaker et cetera. This is the first paper that seeks to shed some light on the long debate concerning the transactional efficiency as a necessary condition for the informational efficiency and allocational efficiency. The GST imposition may lead to a change in the market efficiency. Figure 1 shows the classification of market efficiency.

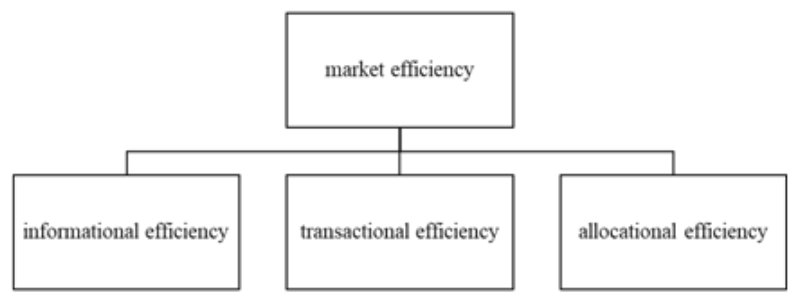

Figures 1. The Classification of Market Efficiency 
This rest of this paper is organised as follows: Section 2 reviews the previous literature and formulates the hypotheses of this paper. Section 3 presents the data, definitions of the variables and research methodology. Section 4 discusses the empirical findings of the GJR-GARCH and switching Generalized Autoregressive Conditional Heteroscedasticity (SGARCH). Section 5 concludes the paper, highlights the limitations and provides suggestions for future research.

\section{Literature Review}

To investigate the presence of leverage effect owing to irrational investors, this paper analyses the asymmetry responses of the investors after the GST imposition on the fee-based financial services. Basically, there are two types of GARCH model: (1) symmetry GARCH and (2) asymmetry GARCH (Liu \& Hung, 2010). The symmetry GARCH assumes that positive news shocks and negative news shocks have a symmetry effect on the stock market volatility. In contrary, the asymmetry GARCH has different assumptions. The asymmetry GARCH models consist of three prevalence model specifications, including (1) exponential GARCH model (EGARCH), (2) GJR-GARCH model and (3) asymmetry power ARCH (APARCH) model (Rahmani, 2016). These three models analyse the relationships between the conditional variance of stock returns and information, by considering the leverage effect on the stock market volatility. In addition, they defined the weight of positive news shocks and negative news shocks differently. By taking into consideration of asymmetry responses, the asymmetry GARCH provides more accurate stock market volatility predictions, by stipulating the error distribution to cope with leptokurtosis, skewness, fat-tails and leverage effect (Awartani \& Corradi, 2005; Evans \& McMillan, 2007; Rahmani, 2016). Among the asymmetry GARCH models, GJR-GARCH model is the most alike to the SGARCH. Moreover, in case of the absence of the leverage effect, the GJR-GARCH model will be reduced to the standard GARCH $(1,1)$ model. For that reason, the GJR-GARCH is employed to enable the comparison with SGARCH and the possibility to reduce to the standard GARCH $(1,1)$ model.

SGARCH is adopted to explore the effect of GST imposition on stock market efficiency. Lee and Ohk (1992) are one of the pioneers to examine the effect of stock index futures listing on the market efficiency of the underlying index in Australia, Hong Kong, Japan, United Kingdom and the United States by using SGARCH. According to them, the stock index futures listing may change the speed of the information assimilation in the stock market and consequence to a structural change in time-varying volatility. They construct an equally-weighted international portfolio and a value-weighted international portfolio to restrain from the country-specific determinants and global factors. To see the effect of one country affecting the portfolio results, they eliminate one country at a time. They found that the stock markets are more efficient after the listing of the index futures by virtue of the volatility shocks being assimilated quicker. The paper does not attempt to relate to the modern finance theory (e.g. EMH) or behavioural finance (e.g. prospect theory).

In a separate study, Baltagi et al. (2006) used more than 230 daily observations in the Shanghai A Share Index and the Shenzhen A Share Index to scrutinise the effect of increased stamp tax rate on the stock market behaviour. The increased of stamp tax rate from $0.3 \%$ to $0.5 \%$ implies that the transaction cost increases about one-third. B share markets is excluded due to the thinness of trading. Moreover, trading in B share markets does not exceed $1 \%$ of the total trading in both A and B share markets. Thus, the Shanghai A Index and Shenzhen A Share Index are compiled based on the weighted market capitalisations and include all listed A-Share stocks. There are over 230 daily observations over the six-month interval from the 10th May 1997. Accordingly, SGARCH is used to capture the structural change in the conditional variance equation (which represents a change in the market efficiency). They uncovered that there is a significantly negative relationship between increases in stamp tax rate and the market efficiency, which is opposite to the aim of the policymaker. One of the limitations with the paper is that the empirical results only represent the Shanghai and Shenzhen stock market. Thus, generalisation is impossible.

Su and Zheng (2010) examined the effect of changes of Securities Transaction Taxes (STT) rate on the market efficiency of local A-shares market in China. Similar to Baltagi et al. (2006), they decided to use A-shares because A-shares dominate the stock market regarding the number of listing companies, trading volume and market value. $0.6 \%$ of STT was imposed on the purchase and sale of A-shares in Shenzhen Stock Exchange since the launch. Effective from 10th October 1991 onwards, 0.3\% of STT was imposed on the purchase and sale of A-shares in Shanghai Stock Exchange. There is a total of five increments and nine reductions in the STT rate over the year. They reveal that the STT has an insignificant relationship with the market efficiency. The inconclusive findings in the paper reflect its consistency with the EMH. The STT as a form of friction in a stock market is not a necessary condition for the market inefficiency.

Perhaps the most serious disadvantages of the aforementioned analyses are that they assume a Gaussian normal 
distribution by the inclusion of first-order moving average in the SGARCH model. Besides, they have been focused on the changes of informational efficiency without relating it to transactional efficiency. Moreover, their studies do not attempt to compare the GJR-GARCH model and the SGARCH model. They also did not offer the explanation of the empirical findings via the modern finance theory or behavioural finance theory.

The hypotheses are formulated as follows. The conceptual framework is as illustrated in Figure 2.

$\mathrm{H}_{1}$ : An asymmetry response towards the negative news shocks is observed during the GST imposition.

$\mathrm{H}_{2}$ : GST imposition has a significant relationship with the market efficiency.

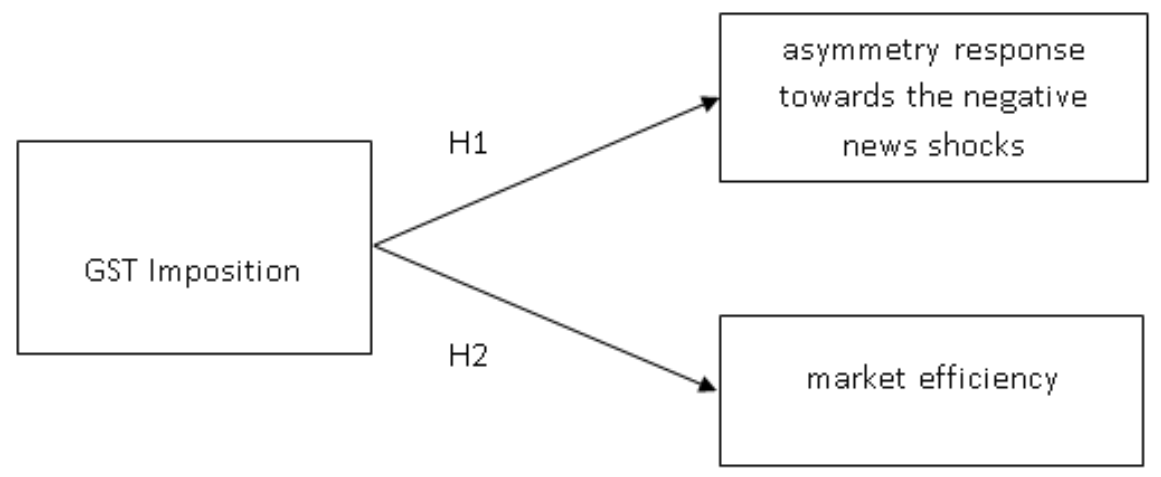

Figure 2. The Conceptual Framework

\section{Data and Methodology}

\subsection{Data}

This paper explores the presence of asymmetry responses towards the negative news shocks and the changes of market efficiency after the GST imposition on fee-based financial services in Bursa Malaysia and ASX. There are three motivations to conduct this research in Bursa Malaysia and ASX in relation to the GST imposition. Firstly, most countries exempt all financial services from GST, but Malaysia and Australia are among the pioneers to impose GST on fee-based financial services, particularly on the clearing fee and brokerage commission (KPMG, 2013). Secondly, despite the news about GST implementation being announced prior to the actual GST implementation date, GST implementation is often associated with continuous protests and a further deferment after the announcement. Thus, it is more interesting to investigate the asymmetry response of the investors towards the news shocks of the actual GST imposition. Thirdly, the GST imposed on the fee-based financial services is not as substantial as the FTT. However, it does improve the revenue that is generated from the financial sector due to the frequency of tradings. Hence, it is worthwhile for the policymaker to contemplate on imposing GST on the fee-based financial services, rather than the FTT that "throw sands in the wheel of the financial markets" (Tobin, 1978).

The daily official closing price and annual market capitalisation of the companies listed in Bursa Malaysia and ASX are collected from Datastream, Thomson Reuters. Companies with incomplete daily official closing price or annual market capitalisation are excluded from this paper. Accordingly, the daily natural logarithm stock returns as expressed in Equation 1 is computed by using the daily official closing price (Ali, Nassir, Abidin \& Talib, 2011; Hvozdyk \& Rustanov, 2016). There are two advantages of the natural logarithm stock returns: (1) it conforms to the normality assumption and (2) relating the natural logarithmic stock returns over a relatively longer research period is more manageable (Strong, 1992).

$$
r_{t}=\ln \left(p_{t} / p_{t-1}\right) * 100
$$

where,

$p_{t}=$ the stock price at time $\mathrm{t}$,

$p_{t+1}=$ the stock price at time $\mathrm{t}+1$, and

$\ln =$ the natural logarithm.

The weighted market capitalisation method is then employed to construct the one joint portfolio and the ten size-sorted decile portfolios by using weighted adjusted stock returns. The weight of the stocks, $w_{i}$ is given as $w_{i}$ $=c_{i} / c_{t}$, 
where,

$c_{i}=$ the market capitalisation of stock $\mathrm{i}$,

$c_{t}=$ the market capitalisation of all stocks in the Bursa Malaysia and ASX, respectively.

One joint portfolio comprises of all companies in Bursa Malaysia and ASX respectively, to explore the effect of GST imposition on the changes of market efficiency. Ten size-sorted portfolios are constructed based on market capitalisation to study the moderating role of the size effect to moderate the relationship between the GST imposition on the fee-based financial services with the market efficiency (Hvozdyk \& Rustanov, 2016). The decile portfolio with the smallest market capitalisation is indicated as Portfolio 1, while those with the largest market capitalisation is represented by Portfolio 10 .

The research period is one-year before and after the GST imposition (on the fee-based financial services) in Bursa Malaysia and ASX. Weekends and holidays are excluded from the research period. The GST imposition date for both Malaysia and Australia is considered as the event day, which is 1st April 2015 and 1st July 2000, correspondingly. Therefore, the research period of Bursa Malaysia and ASX is from 1st April 2014 to 31st March 2016 and from 1st July 1999 to 30th June 2001, respectively. The research period is divided into two sub-periods: (1) pre-GST imposition and (2) post-GST imposition.

\subsection{GJR-GARCH and SGARCH}

Stock returns are not normally distributed with significant leptokurtosis and skewness (Berry, Gallinger \& Henderson, 1990; Pagan \& Schwert, 1990; Hamid et al., 2010; Huber, Kleinlercher \& Kirchler, 2012; Huang, Lin, Wang \& Chiu, 2014). The variance of the stock returns is associated with the uncertainty or risk and leads to the persistence of the stock market volatility. Accordingly, Engle (1982) incorporated the time-varying stock market volatility in the way that, the conditional variance is a function of the past squared errors. This is known as Autoregressive Conditional Heteroscedasticity (ARCH) model. It can be written as in equation 1.

$$
\operatorname{var}\left(\varepsilon_{t} \mid I_{t-1}\right) \equiv \sigma_{t}^{2}=\alpha_{0}+\alpha_{1} \varepsilon_{t-1}^{2}+\alpha_{2} \varepsilon_{t-2}^{2}+\ldots+\alpha_{q} \varepsilon_{t-q}^{2}
$$

where,

$I_{t-1}=$ the information set up for period $t-1$,

$\sigma_{t}^{2}=$ conditional variance at time $t$,

$\varepsilon_{t-1}^{2}=$ past squared error at time $t-1$,

$\varepsilon_{t-2}^{2}=$ past squared error at time $t-2$,

$\varepsilon_{t-q}^{2}=$ past squared error at time $t-q$.

The ARCH model is often accompanied with long lag length, $q$. In an attempt to extend the ARCH model, Bollerslev (1986) introduced the Generalized ARCH (GARCH) model, in which, the conditional variance is a function of both past squared error and past conditional variance as written in Equation 2. Unlike ARCH, a small lag in GARCH $(1,1)$ model is adequate to explain the time-varying stock market volatility (Franses, Philip Hans \& Dick Van Dijk, 1996).

$$
\operatorname{var}\left(\varepsilon_{t} \mid I_{t-1}\right) \equiv \sigma_{t}^{2}=\alpha_{0}+\alpha_{1} \varepsilon_{t-1}^{2}+\alpha_{2} \sigma_{t-1}^{2}
$$

where,

$I_{t-1}=$ the information set up for period $t-1$,

$\sigma_{t}^{2}=$ conditional variance at time $t$,

$\varepsilon_{t-1}^{2}=$ past squared error at time $t-1$,

$\sigma_{t-1}^{2}=$ past conditional variance at time $\mathrm{t}-1$.

Nevertheless, GARCH model has been criticized for failing to capture the asymmetric responses stemmed from positive and negative news shocks. Moreover, due to substantial empirical evidence exists of non-normal distribution of financial returns, previous studies have proposed various error distributions to alleviate the deficiency of normal assumption. One of the most recent asymmetric GARCH models is the threshold GARCH by Glosten, Jagannathan and Runkle (1993) (GJR-GARCH).

The GJR-GARCH model is known as the threshold GARCH model. It allows for the leverage effect attributable to the positive and negative news shocks. The GJR-GARCH can be expressed as Equation 3 (Hyung, Poon \& Granger, 2006). 


$$
\operatorname{var}\left(\varepsilon_{t} \mid I_{t-1}\right) \equiv \sigma_{t}^{2}=\alpha_{0}+\alpha_{1} \varepsilon_{t-1}^{2} I_{\varepsilon_{t-1 \leq 1}}+\alpha_{2} \varepsilon_{t-1}^{2} I_{\varepsilon_{t-1>1}}+\alpha_{3} \sigma_{t-1}^{2}
$$

where,

$I_{t-1}=$ the information set up for period $\mathrm{t}-1$,

$\sigma_{t}^{2}=$ conditional variance at time $\mathrm{t}$,

$\varepsilon_{t-1}^{2}=$ past squared error at time $\mathrm{t}-1$,

$\sigma_{t-1}^{2}=$ past conditional variance at time $\mathrm{t}-1$,

$$
I_{\varepsilon_{t-1}}=\left\{\begin{array}{l}
0 \text { if } \varepsilon_{t-1}<0 \\
1 \text { otherwise }
\end{array}\right.
$$

$I_{\varepsilon_{t-1}}$ distinguishes between the positive news shocks and the negative news shocks by using $\alpha_{2}$ to capture the presence of the asymmetric responses. Thus, in the GJR-GARCH model, the positive news shocks have an impact of $\alpha_{1}$, whilst the negative news shocks have an impact of $\alpha_{1}+\alpha_{2}$. The positive and highly significant $\alpha_{2}$ in the conditional variance equation imply that negative news shocks exert a greater effect on stock market volatility compared to positive news shocks with the same magnitude. In case the $\alpha_{2}$ is insignificant, the GJR-GARCH model is reduced to GARCH $(1,1)$ model (Rapach, Strauss \& Wohar, 2008). This infers that both positive and negative news shocks have symmetric effects on stock market volatility.

On the other hand, to capture structural change in time-varying volatility (i.e. change in the level and slope) in the stock market, the switching GARCH implements an autoregressive structure on the conditional variance to allows the persistent of stock market volatility shocks using dummy variables, D (Lee \& Ohk, 1992; Baltagi et al., 2006; Su \& Zheng, 2010). The switching GARCH is derived from two GARCH processes as follows.

$$
r_{t}=\beta_{0}+\mu_{t}
$$

where,

$r_{t}=$ the stock returns at time $t$,

$\mu_{t}=\varepsilon_{t}-\theta \varepsilon_{t-1}$, and

$\varepsilon_{t} \mid I_{t-1} \sim N\left(0, \sigma_{t}^{2}\right)$.

$$
\begin{array}{rlr}
\sigma_{t}^{2}=\alpha_{0 \alpha}+\alpha_{1 \alpha} \varepsilon_{t-1}^{2}+\alpha_{2 \alpha} \sigma_{t-1}^{2} & \left(t=1,2, \ldots, t^{*}-1\right) \\
\sigma_{t}^{2}=\alpha_{0 \beta}+\alpha_{1 \beta} \varepsilon_{t-1}^{2}+\alpha_{2 \beta} \sigma_{t-1}^{2} & \left(t=t^{*}, t^{*}+1, \ldots, T\right)
\end{array}
$$

where,

$\sigma_{t}^{2}=$ volatility at time $\mathrm{t}$, is also the function of past error squared and conditional variance,

$I_{t-1}=$ all relevant and available information at time $\mathrm{t}-1$.

$\varepsilon_{t-1}^{2}=$ past squared error at time $t-1$, and

$\sigma_{t-1}^{2}=$ past conditional variance at time $\mathrm{t}-1$.

The misrepresentation of parameter estimates resulting from the serial correlation can be overcome by involving a first-order moving average (Lee \& Ohk, 1992). As such, $\varepsilon_{t}$ is normally distributed (Lee \& Ohk, 1992). However, unlike Lee and Ohk (1992), this paper plotted the Autocorrelation Function (ACF) and Partial Autocorrelation Function (PACF) by using the sample autocorrelations against the time lags to decide the inclusion of the autoregressive or moving average. In addition, owing to the small sample size in the ten size-sorted portfolios, Student's t-distribution is employed rather than using the assumption of normal distribution. The adoption of Student's t-distribution is supported by the empirical results from the Kolmogorov-Smirnov, which prove that the samples are not normally distributed. 
The GST imposition on fee-based financial services date is considered as a switching point, $\mathrm{t}^{*}$. Equation 5 and 6 can be simplified as the mean equation in Equation 7 and the conditional variance equation in Equation 8.

$$
\begin{gathered}
r_{t}=\mu_{0}+\mu_{1} D_{t}+\varepsilon_{t} \\
\operatorname{var}\left(\varepsilon_{t} \mid I_{t-1}\right) \equiv \sigma_{t}^{2}=\alpha_{0}+\alpha_{1} \varepsilon_{t-1}^{2}+\alpha_{2} \sigma_{t-1}^{2}+\alpha_{3} D t+\alpha_{4} D t \varepsilon_{t-1}^{2}+\alpha_{5} D_{t} \sigma_{t-1}^{2}
\end{gathered}
$$

where,

$$
D t=\left\{\begin{array}{c}
0 \text { if } 1 \leq t \leq t *-1 \\
1 \text { if } t * t \leq T
\end{array}\right.
$$

$\alpha_{3}=\alpha_{0 \beta}-\alpha_{0 \alpha}, \alpha_{4}=\alpha_{1 \beta}-\alpha_{1 \alpha}$ and $\alpha_{5}=\alpha_{2 \beta}-\alpha_{2 \alpha}$

The dummy in the equation 7 represents the variation of the mean stock returns due to the GST imposition on the fee-based financial services. The dummies in the conditional variance Equation 8 denotes the switching in the autoregressive structure, which can be interpreted as the switching of market efficiency.

The null hypothesis is; none of the dummy coefficients is significantly different from zero (Lee \& Ohk, 1992; Baltagi et al., 2006; Su \& Zheng, 2010). This suggests that there is no switching in the autoregressive structure and no change in market efficiency after the GST imposition on fee-based financial services. In contrast, a significant in either one of the dummy coefficients infers a switching in the autoregressive structure (Lee \& Ohk, 1992; Baltagi et al., 2006; Su \& Zheng, 2010).

$\mathrm{H}_{0}: \alpha_{3}=\alpha_{4}=\alpha_{5}=0$

$\mathrm{H}_{\mathrm{a}}$ : either one of the $\alpha_{3}, \alpha_{4}$ or $\alpha_{5} \neq 0$

There are three assumptions of error normality for a classical linear regression model: (1) The expected value of the error is always zero, given by the value of $x$. (2) The variances of error do not vary with the values of x. (3) The covariance between any pair of error is always equal to zero. Under the assumption of error normality, the log-likelihood function of the SGARCH model is stated as Equation 10 (Lee \& Ohk, 1992; Baltagi et al., 2006; Su \& Zheng, 2010).

$$
L=\sum-\frac{1}{2}\left(\operatorname{In}(2 \pi)+\operatorname{In} \sigma_{t}^{2}+\frac{\varepsilon_{t}^{2}}{\sigma_{t}^{2}}\right)
$$

The non-linear optimisation method is estimated using Maximum Likelihood Estimation (MLE) with BHHH algorithm (Lee \& Ohk, 1992; Su \& Zheng, 2010). In the SGARCH model, a negative $\alpha_{4}$ and a positive $\alpha_{5}$ imply that after the GST imposition, the effect of $\varepsilon_{t-1}^{2}$ on $\sigma_{t}^{2}$ at time $t$ decreases, but the effect of $\sigma_{t-1}^{2}$ on $\sigma_{t}^{2}$ at time $t$ increases (Lee \& Ohk, 1992; Baltagi et al., 2006; Su \& Zheng, 2010). The $\varepsilon_{t-1}^{2}$ represents the news shocks at time $t-1$, whilst the $\sigma_{t-1}^{2}$ represents the conditional variance of the stock returns at time $t-1$. Therefore, after the GST imposition, the news shocks are less quickly assimilated in the stock markets because GST is a form of friction to slow down the assimilation. In addition, the past conditional stock market volatility has more explanatory power on the current conditional stock market volatility. This shows that the stock market has become less efficient and more predictable.

In contrast, a positive $\alpha_{4}$ and a negative $\alpha_{5}$ imply that after the GST imposition, the effect of $\varepsilon_{t-1}^{2}$ on $\sigma_{t}^{2}$ at time $t$ increases, but the effect of $\sigma_{t-1}^{2}$ on $\sigma_{t}^{2}$ at time $t$ decreases (Lee \& Ohk, 1992; Baltagi et al., 2006; Su \& Zheng, 2010). After the GST imposition, the news shocks are reflected quickly in the stock markets because the GST is a negligible friction in the stock market. Meanwhile, the past conditional stock market volatility has less explanatory power on the current conditional stock market volatility. Hence, the stock market becomes more efficient and less predictable. The same sign for the $\alpha_{4}$ and $\alpha_{5}$ have little said about the stock market efficiency (Lee \& Ohk, 1992; Baltagi et al., 2006; Su \& Zheng, 2010).

Comparing the GJR-GARCH in the Equation 3 and the switching GARCH in Equation 8, it is clear that the dummy variable $I_{t-l}$ is determined by the value of $\varepsilon_{t-l}$, whilst the $D_{t}$ is predetermined by using the event date. The SGARCH in the Equation 8 contains two interaction variables, particularly between the dummy variable with the past squared error and the past conditional stock market volatility. Unlike SGARCH, the GJR-GARCH in the Equation 3 contains one interaction variable between the dummy variable with the past squared error. 


\section{Results and Discussions}

Table 1. The Presence of Leverage Effect in Bursa Malaysia

\begin{tabular}{|c|c|c|c|c|}
\hline \multicolumn{5}{|c|}{ GJR-GARCH Model } \\
\hline Portfolio & $\alpha_{0}$ & $\alpha_{1}$ & $\boldsymbol{\alpha}_{2}$ & $\alpha_{3}$ \\
\hline One-Joint & $0.001 * * *$ & $-0.034 * * *$ & $0.034 * * *$ & $1.013 * * *$ \\
\hline 1 & 1.154 & 0.002 & 1.204 & $0.448 * *$ \\
\hline 2 & 27.556 & 0.007 & 0.055 & 0.397 \\
\hline 3 & $0.302 * *$ & 0.001 & $0.613 * *$ & $0.575 * * *$ \\
\hline 4 & $0.401 *$ & 0.006 & $0.711 *$ & $0.410 * * *$ \\
\hline 5 & $0.048 *$ & 0.061 & 0.122 & $0.820 * * *$ \\
\hline 6 & $0.110 * * *$ & 0.129 & 0.237 & $0.640 * * *$ \\
\hline 7 & 0.040 & 0.070 & -0.069 & $0.946 * * *$ \\
\hline 8 & $0.141 * *$ & 0.124 & 0.320 & $0.604 * * *$ \\
\hline 9 & 0.079 & 0.242 & -0.241 & $0.887 * * *$ \\
\hline 10 & $0.001 * * *$ & $-0.034 * * *$ & $0.034 * * *$ & $1.014 * * *$ \\
\hline
\end{tabular}

$* \mathrm{p}<0.05, * * \mathrm{p}<0.01$ and $* * * \mathrm{p}<0.001$.

Table 2. The Presence of Leverage Effect in Australian Securities Exchange (ASX)

\begin{tabular}{|c|c|c|c|c|}
\hline \multicolumn{5}{|c|}{ GJR-GARCH Model } \\
\hline Portfolio & $\boldsymbol{\alpha}_{0}$ & $\alpha_{1}$ & $\boldsymbol{\alpha}_{2}$ & $\boldsymbol{\alpha}_{3}$ \\
\hline One-Joint & 0.022 & -0.015 & $0.128 * *$ & $0.904 * * *$ \\
\hline 1 & $1.824 * * *$ & $0.397 *$ & -0.040 & 0.036 \\
\hline 2 & $0.190 *$ & $0.172 * *$ & -0.024 & $0.752 * * *$ \\
\hline 3 & $0.283 * *$ & 0.117 & 0.041 & $0.725 * * *$ \\
\hline 4 & $0.141 *$ & $0.140 *$ & -0.089 & $0.849 * * *$ \\
\hline 5 & $0.110 *$ & 0.086 & 0.021 & $0.803 * * *$ \\
\hline 6 & $0.259 *$ & 0.089 & 0.092 & $0.709 * * *$ \\
\hline 7 & $0.402 * *$ & 0.113 & 0.064 & $0.466 * *$ \\
\hline 8 & 0.063 & 0.035 & 0.052 & $0.842 * * *$ \\
\hline 9 & 0.207 & 0.025 & 0.052 & 0.145 \\
\hline 10 & 0.023 & -0.009 & $0.120 *$ & $0.906 * * *$ \\
\hline
\end{tabular}

$* \mathrm{p}<0.05, * * \mathrm{p}<0.01$ and $* * * \mathrm{p}<0.001$.

Table 3. Standard GARCH $(1,1)$ Model in Bursa Malaysia

\begin{tabular}{cccc}
\hline & \multicolumn{2}{c}{ Standard GARCH (1,1) Model } & $\boldsymbol{\alpha}_{\mathbf{2}}$ \\
\hline Portfolio & $\boldsymbol{\alpha}_{\mathbf{0}}$ & $\boldsymbol{\alpha}_{\mathbf{1}}$ & $0.998 * * *$ \\
\hline One-Joint & $0.002 *$ & 0.000 & 0.018 \\
1 & 2.464 & 0.003 & 0.148 \\
2 & 1.267 & 0.000 & $0.985 * * *$ \\
3 & 0.031 & 0.000 & 0.143 \\
4 & $0.716^{*}$ & 0.865 & $0.834 * * *$ \\
5 & $0.042^{*}$ & $0.144 * *$ & $0.666 * * *$ \\
6 & $0.098^{* *}$ & $0.291 * *$ & $0.239 * *$ \\
7 & $0.331 * * *$ & $0.571 * *$ & $-0.986 * * *$ \\
8 & 3.861 & 0.000 & $0.930 * * *$ \\
9 & 0.066 & 0.001 & $0.993 * * *$ \\
\hline
\end{tabular}

$* \mathrm{p}<0.05, * * \mathrm{p}<0.01$ and $* * * \mathrm{p}<0.001$.

Table 4. Switching of Market Efficiency in Bursa Malaysia After the GST Imposition

\begin{tabular}{ccccccccc}
\hline Portfolio & $\boldsymbol{\mu}_{\mathbf{0}}$ & $\boldsymbol{\mu}_{\mathbf{1}}$ & $\boldsymbol{\alpha}_{\mathbf{0}}$ & $\boldsymbol{\alpha}_{\mathbf{1}}$ & $\boldsymbol{\alpha}_{\mathbf{2}}$ & $\boldsymbol{\alpha}_{\mathbf{3}}$ & $\boldsymbol{\alpha}_{\mathbf{4}}$ & $\boldsymbol{\alpha}_{\mathbf{5}}$ \\
\hline One-Joint & 0.022 & -0.016 & 0.007 & $0.111^{*}$ & $0.899 * * *$ & -0.904 & $-0.111 *$ & 0.010 \\
1 & 0.112 & -0.094 & 10.340 & 0.062 & $-0.122 * *$ & -4.590 & -0.061 & -0.158 \\
2 & $0.144 * *$ & -0.092 & 0.069 & 0.071 & $0.882 * * *$ & 1.002 & -0.0712 & -0.023 \\
3 & $0.143 * * *$ & -0.051 & 0.056 & $0.148 *$ & $0.856 * * *$ & 2.122 & $-0.148 *$ & -0.154 \\
4 & $0.089 * *$ & 0.024 & 0.101 & 0.212 & $0.759 * * *$ & 4.508 & -0.212 & -0.513 \\
5 & $0.141 * * *$ & -0.018 & 0.029 & 0.143 & 0.837 & 0.090 & $4.23 \mathrm{E}-05$ & -0.093 \\
6 & $0.108 * * *$ & 0.069 & 0.038 & $0.347 *$ & $0.743 * * *$ & 9.087 & $-0.357 *$ & -2.561 \\
7 & $0.092 * * *$ & 0.054 & 0.078 & $0.537 *$ & $0.564 * * *$ & 0.037 & $-0.537 *$ & 0.023 \\
8 & $0.063 *$ & -0.005 & 0.052 & 0.351 & $0.807 * * *$ & 6.089 & -0.352 & -1.061 \\
9 & 0.034 & 0.027 & 0.018 & $0.173 *$ & $0.850 * * *$ & 2.347 & $-0.173 *$ & -0.068 \\
10 & 0.010 & -0.023 & 0.007 & 0.113 & $0.902 * * *$ & -1.130 & -0.112 & 0.009 \\
\hline
\end{tabular}

$* \mathrm{p}<0.05, * * \mathrm{p}<0.01$ and $* * * \mathrm{p}<0.001$. 
Table 5. Standard GARCH $(1,1)$ Model in Australian Securities Exchange (ASX)

\begin{tabular}{cccc}
\hline & \multicolumn{2}{c}{ Standard GARCH (1,1) Model } & $\boldsymbol{\alpha}_{\mathbf{2}}$ \\
\hline Portfolio & $\boldsymbol{\alpha}_{\mathbf{0}}$ & $\boldsymbol{\alpha}_{1}$ & 0.268 \\
One-Joint & 0.302 & 0.136 & 0.033 \\
1 & $1.835 * * *$ & $0.374 * *$ & $0.747 * * *$ \\
2 & $0.194 * *$ & $0.165 * * *$ & $0.736 * * *$ \\
3 & $0.269 * *$ & $0.134 * *$ & $0.797 * * *$ \\
4 & $0.209 *$ & $0.113 * *$ & $0.807 * * *$ \\
5 & $0.107 *$ & $0.095 * *$ & $0.715 * * *$ \\
6 & $0.255^{*}$ & $0.132 *$ & $0.459 * *$ \\
7 & $0.412 * *$ & $0.148 *$ & $0.859 * * *$ \\
8 & 0.055 & 0.059 & -0.314 \\
9 & 0.328 & 0.044 & 0.258 \\
\hline
\end{tabular}

$* \mathrm{p}<0.05, * * \mathrm{p}<0.01$ and $* * * \mathrm{p}<0.001$.

Table 6. Switching of Market Efficiency in Australian Securities Exchange (ASX) After the GST Imposition

\begin{tabular}{ccccccccc}
\hline Portfolio & $\boldsymbol{\mu}_{\mathbf{0}}$ & $\boldsymbol{\mu}_{\mathbf{1}}$ & $\boldsymbol{\alpha}_{\mathbf{0}}$ & $\boldsymbol{\alpha}_{\mathbf{1}}$ & $\boldsymbol{\alpha}_{\mathbf{2}}$ & $\boldsymbol{\alpha}_{\mathbf{3}}$ & $\boldsymbol{\alpha}_{\mathbf{4}}$ & $\boldsymbol{\alpha}_{\mathbf{5}}$ \\
\hline One-Joint & 0.019 & 0.059 & $0.441 *$ & 0.239 & 0.118 & 0.176 & -0.154 & -0.688 \\
1 & 0.017 & $-0.355 * *$ & $1.833 * * *$ & $0.357 *$ & 0.052 & -0.816 & -0.025 & 0.240 \\
2 & 0.081 & $-0.393 * * *$ & 0.181 & $0.162 * *$ & $0.786 * * *$ & 0.088 & -0.036 & -0.110 \\
3 & $0.183 *$ & $-0.369 * * *$ & $0.306 *$ & $0.099 *$ & $0.764 * * *$ & 0.035 & 0.086 & -0.129 \\
4 & $0.303 * * *$ & $-0.612 * * *$ & $1.100 * *$ & $0.352 *$ & $0.369 * *$ & -0.638 & $-0.383 *$ & 0.283 \\
5 & 0.076 & -0.149 & 0.128 & $0.125 *$ & $0.787 * * *$ & 0.018 & -0.141 & 0.024 \\
6 & $0.169 *$ & $-0.280 * *$ & 0.336 & 0.114 & $0.718 * * *$ & -0.026 & 0.080 & -0.139 \\
7 & $0.147 * *$ & $-0.229 * *$ & $0.797 * *$ & 0.135 & 0.095 & -0.402 & -0.175 & 0.519 \\
8 & 0.068 & -0.016 & 0.045 & 0.037 & $0.908 * * *$ & 0.032 & 0.047 & -0.125 \\
9 & -0.011 & 0.049 & 0.001 & $-0.010 *$ & $1.009 * * *$ & $0.154 * *$ & 0.010 & $-0.594 * *$ \\
10 & 0.018 & 0.062 & $0.484 *$ & 0.245 & 0.119 & -0.499 & $-0.292 *$ & 0.792 \\
\hline
\end{tabular}

$* \mathrm{p}<0.05, * * \mathrm{p}<0.01$ and $* * * \mathrm{p}<0.001$.

This section reports the (1) presence of leverage effect and (2) effect of GST imposition on market efficiency in Bursa Malaysia and ASX. Table 1 and 2 depict the leverage effect in Bursa Malaysia and ASX, respectively. The standard GARCH $(1,1)$ model and the switching of time-varying volatility or the market efficiency in the Bursa Malaysia are accordingly presented separately in Table 3 and 4. Table 5 and 6 summarise the standard GARCH $(1,1)$ model and the changes of market efficiency in the ASX. One joint portfolio is weighted by utilising the market capitalisation of all stocks in the stock market. For that reason, the one joint portfolio constitutes the all-inclusive asymmetric response and structural change of the market efficiency in the stock market. To further analyse the role of the size effect as a moderator, ten size-sorted portfolios are constructed by making use of the weighted adjusted stock returns (Hvozdyk \& Rustanov, 2016).

$\alpha_{0}$ in the GJR-GARCH model is the constant. Despite $\alpha_{0}$ in the GJR-GARCH model of Bursa Malaysia being highly significant $(p<0.001)$, the magnitude of the coefficient of 0.001 is negligible. In the same manner, $\alpha_{1}$ in the GJR-GARCH model of ASX is insignificant. This entails that there are no other influences or noise embedded in the constant of both stock markets. As stated in subsection 3.2, the positive news shocks are expected to be indicated by the $\alpha_{1}$, whereas, the asymmetric responses towards the negative news shocks are denoted by the $\alpha_{2}$ in the GJR-GARCH model. Thus, the leverage effect is present in both Bursa Malaysia and ASX by virtue of the $\alpha_{2}$ being significant. Nevertheless, the empirical finding of $\alpha_{l}$ in Bursa Malaysia and ASX is against Ling and McAleer (2002) concerning $\alpha_{1}, \alpha_{2}$ and $\alpha_{3}$ being non-negative parameters. Unlike Bursa Malaysia with $\alpha_{2}$ of 0.034, the negative news shocks in ASX exert a greater asymmetry effect of 0.128 than the positive news shocks in ASX. As expected, the effect of past stock market volatility on current stock market volatility is substantial than the effect of the news shocks, with a significant coefficient for both Bursa Malaysia and ASX. In addition, no trend is observed with regards to the size effect to moderate the leverage effect in Bursa Malaysia and ASX.

Taken together, the aforementioned empirical findings demonstrate a significant leverage effect in the Bursa Malaysia and ASX that is attributable to the heuristics of irrational investors in both developing market and developed market. A heuristic is a strategy to solve the complicated problem via simple judgemental procedures (Kahneman \& Tversky, 1979). In this respect, the leverage effect in Bursa Malaysia and ASX is due to the disparities in the investors' decision making towards gains and losses based on the news shocks. Coincidental with the Prospect Theory, investors alter their behaviour to sidestep the pain of regret with wrong beliefs due to loss aversion. From the perspective of academic contribution, the empirical results support the Adaptive Market 
Hypothesis (AMH) more than EMH. AMH reconciled the market efficiency with the behavioural alternatives to form financial interactions by using the principles of evolution (including the competition, adaptation, and natural selection) (Lo, 2004). Nevertheless, to-date, the modern finance theory has been dominant in explaining financial markets with the caveats of irrational investors. Therefore, scholars should pay attention on behavioural finance in the future research. The policy market may consider educating investors regarding heuristics to reduce the irrational behaviours and stabilise the stock market.

To decide on the inclusion of autoregressive or moving average in the SGARCH model, the theoretical patterns of AF and PACF (as shown in the Appendix A and B) were obtained for Bursa Malaysia and ASX. Overall, there is no evidence of exponential decay or cut-off after the lags of $\mathrm{p}$ or $\mathrm{q}$. On that account, no autoregressive or moving average is included in the SGARCH. As mentioned in subsection 3.2, the persistence of volatility shocks for before the GST imposition on the fee-based financial services is equivalent to the sum of $\alpha_{1}$ and $\alpha_{2}$ in SGARCH model. After the GST imposition on the fee-based financial services, the volatility persistence is represented by the sum of $\alpha_{1}, \alpha_{2}, \alpha_{4}$ and $\alpha_{5}$ in SGARCH. In Bursa Malaysia, the persistence of volatility shocks reduced from 1.01 to 0.909 after the GST imposition. In the same manner, the persistence of volatility in ASX drastically declined from 0.357 to -0.485 . In the SGARCH model, $\mu_{l}$, the dummy coefficient in the mean equation) signifies the rate of stock return after the GST imposition. An insignificant $\mu_{l}$ in one joint portfolio and ten size-sorted portfolios of Bursa Malaysia infers that the GST imposition on fee-based financial services does not affect the rate of the stock returns. Unlike Bursa Malaysia, Portfolio 1, 2, 3, 4, 6 and 7 in ASX have significantly negative $\mu_{l}$. This signals that although the rate of stock returns in Portfolio 1, 2, 3, 4, 6 and 7 of ASX significantly declined after the GST imposition on the fee-based financial services, from the macro point of view, there is no reduction in the rate of stock returns.

The dummy coefficients of $\alpha_{3}, \alpha_{4}$ and $\alpha_{5}$ in the conditional variance equation showed evidence on the changes in the market efficiency. In Bursa Malaysia, $\alpha_{4}$ of one joint portfolio, portfolio 3, 6, 7 and 9 are significantly negative, but both $\alpha_{3}$ and $\alpha_{5}$ are insignificant. A significantly negative $\alpha_{4}$ and an insignificant $\alpha_{5}$ implies that after the GST imposition, the effect of $\varepsilon_{t-1}^{2}$ on $\sigma_{t}^{2}$ at time $t$ decreases, but the effect of $\sigma_{t-1}^{2}$ on $\sigma_{t}^{2}$ at time $t$ remains unchanged (Lee \& Ohk, 1992; Baltagi et al., 2006; Su \& Zheng, 2010). The $\varepsilon_{t-1}^{2}$ represents the news shocks at time $t-1$, whilst the $\sigma_{t-1}^{2}$ represents the conditional variance of the stock returns at time $t-1$. This is to say that the news shocks are less quickly assimilated in Bursa Malaysia after the GST imposition on the fee-based financial services. GST is a sort of friction that inhibits the assimilation of information. Accordingly, Bursa Malaysia responses less promptly to the arrival of the information (i.e. becomes less efficient). In addition, the current conditional stock market volatility is not driven by the past conditional stock market volatility. This proves that the transactional efficiency significantly reduces the informational efficiency. The other portfolios are insignificant and do not experience any changes in market efficiency. Nevertheless, the size effect does not moderate the relationship between the GST imposition on the fee-based financial services and market efficiency in Bursa Malaysia.

In ASX, only $\alpha_{3}$ of portfolio 9, $\alpha_{4}$ of portfolio 4 and 10, as well as $\alpha_{5}$ of portfolio 9 are significant. Similar to Bursa Malaysia, a significantly negative $\alpha_{4}$ and an insignificant $\alpha_{5}$ suggest that the effect of $\varepsilon_{t-1}^{2}$ on $\sigma_{t}^{2}$ at time $t$ decreases, but $\sigma_{t-1}^{2}$ has no effect on the $\sigma_{t}^{2}$ at time $t$ after the GST imposition (Lee \& Ohk, 1992; Baltagi et al., 2006; Su \& Zheng, 2010). The news shocks are less quickly reflected in the stock price and the settling time becomes longer due to the friction attributable to GST imposition in the ASX. Consequently, the past conditional stock market volatility has no influence on the current conditional stock market volatility. This supports the finding that transactional efficiency significantly diminishes informational efficiency. The current conditional stock market volatility is not affected by the past conditional stock market volatility. An insignificant $\alpha_{4}$ and a significantly negative $\alpha_{5}$ in Portfolio 9 denotes that after the GST imposition, the $\varepsilon_{t-1}^{2}$ has no significant effect on the $\sigma_{t}^{2}$ at time $t$, but the effect of $\sigma_{t-1}^{2}$ on $\sigma_{t}^{2}$ at time $t$ significantly reduces (Lee \& Ohk, 1992; Baltagi et al., 2006; Su \& Zheng, 2010). Past news shocks do not affect the current conditional variance of the stock returns. Meanwhile, past conditional stock market volatility affects less on the current conditional stock market volatility after the GST imposition on the fee-based financial services. Nonetheless, $\alpha_{3}, \alpha_{4}$ and $\alpha_{5}$ of one joint portfolio that represents the entire perspectives on the market efficiency do not exhibit any changes. No pattern is shown concerning the moderating role of the size effect on the changes of the market efficiency in ASX. In a nutshell, the aforementioned empirical findings reveal that the GST imposition on fee-based financial services has an insignificant effect on the informational efficiency in ASX.

The ambiguities of the empirical findings are in agreement with the EMH, in which, the absence of transaction costs is a sufficient condition that is not de rigueur to achieve an efficient market. The practical contribution of the empirical findings suggests that GST imposition on the fee-based financial services significantly affects the 
switching of market efficiency in the thin stock market (similar to Bursa Malaysia) but may not have an impact on a developed market (such as ASX). Investors may capitalise on the opportunity to forecast the stock returns, especially, the stock market that has become less efficient after the GST imposition (on the fee-based financial services). On the other hand, the policymakers in a thin market should take extra precaution in devising a GST structure without destabilising the financial market. The policy maker in a developed market may contemplate extending GST on the fee-based financial services without "throwing sands in the wheel of the financial markets" (Tobin, 1978). The GST imposition on the fee-based financial services is a de minimis market friction, but it is enormous for frequently traded short-term speculations.

\section{Conclusions}

This paper documents the presence of leverage effect in Bursa Malaysia and ASX, as well as, the changes of the market efficiency after the GST imposition on fee-based financial services. The empirical findings reveal asymmetry responses that is evidenced by the existence of irrational investors in both developing and developed market. The informational efficiency of Bursa Malaysia is significantly reduced after the GST imposition on fee-based financial services, but not for ASX. This paper contributed to the literature by providing empirical evidence that the increase in transactional costs reduces the speed of the information reflected on the stock price which makes the stock market less efficient, particularly in the thin market (such as, Bursa Malaysia). In other words, the transactional efficiency significantly reduces the informational efficiency of the thin market. As such, this paper provides some valuable evidence on the EMH. Specifically, regarding the transaction cost as a sufficient condition of an efficient market, but not a necessary condition. This makes sense by virtue of the investors having heterogeneous beliefs on the stock market fundamentals (Su \& Zheng, 2010). The divergence in the investors' belief, particularly their mental accounting, offsets each other and make the net effect undistinguishable (Xiong \& Yan, 2010). Together with the empirical findings of leverage effect in Bursa Malaysia and ASX that support the irrational investors, the reconciliation of EMH with the behavioural finance (i.e. AMH) provide new breath for future research. In addition, the policymakers in the developed markets (identical to ASX) should contemplate imposing GST on the fee-based financial services to generate tax revenues without causing stock market instability. The investors could forecast the stock returns of thin markets upon GST imposition on fee-based financial services.

\section{References}

Ali, N., Nassir, A. M., Hassan, T., \& Abidin, S. Z. (2011). Stock overreaction behaviour in Bursa Malaysia: Does the length of formation period matter. British Journal of Economics, 2(2), 42-56.

Arellano, J. P., \& Corbo, V. (2013). Tributación para el Desarrollo: estudios para la reforma del sistema chileno. Santiago: Centro de Estudios Públicos y Cieplan.

Awartani, B. M. A., \& Corradi, V. (2005). Predicting the volatility of the S\&P-500 stock index via GARCH models: The role of asymmetries. International Journal of Forecasting, 21, 167-183. https://doi.org/10.1016/j.ijforecast.2004.08.003

Baltagi, B. H., Li, D., \& Li, Q. (2006). Transaction tax and stock market behavior: Evidence from an emerging market. Empirical Economics, 31(2), 393-408. https://doi.org/10.1007/s00181-005-0022-9

Berry, M. A., Gallinger, G. W., \& Henderson, G. (1990). Using stock returns in event studies and the choice of parametric versus nonparametric test statistics. Quarterly Journal of Business and Economics, 29, 70-85.

Bollerslev, T. (1986). Generalised Autoregressive Conditional Heteroscedasticity. Journal of Econometrics, 31(3), 307-327. https://doi.org/10.1016/0304-4076(86)90063-1

Burman, L. E., Gale, W. G., Gault, S., Kim, B., Nunns, J., \& Rosenthal, S. (2016). Financial transaction taxes in theory and practice. National Tax Journal, 69(1), 171-216. https://doi.org/10.17310/ntj.2016.1.06

Capelle-Blancard, G., \& Havrylchyk, O. (2014). The impact of the French securities transaction tax on market liquidity and volatility, SSRN Working Paper.

Claessens, S., Keen, M., \& Pazarbasioglu, C. (2010). Financial Sector Taxation: The IMF's Report to the G-20 and Background Material. International Monetary Fund.

Cochrane, J. H. (2013). Finance: Function Matters, Not Size. The Journal of Economic Perspectives, 27(2), 29-50. https://doi.org/10.1257/jep.27.2.29

Correa, J., Lorca, M., \& Parro, M. (2015). Measuring the impact of financial taxation on capital, MPRA Paper 64378, University Library of Munich, Germany. 
Engle, R. F. (1982). Autoregressive conditional heteroscedasticity with estimates of the variance of United Kingdom inflation. Econometrica, 50(4), 987. https://doi.org/10.2307/1912773

Evans, T., \& McMillan, D. G. (2007). Volatility forecasts: The role of asymmetric and long-memory dynamics and regional evidence. Applied Financial Economics, 17, 1421-1430. https://doi.org/10.1080/09603100601007149

Fama, E. F. (1970). Efficient capital markets: A review of theory and empirical work. The Journal of Finance, 25(2), 383. https://doi.org/10.2307/2325486

Franses, Philip Hans \& Dick Van Dijk (1996). Forecasting stock market volatility using (non-linear) GARCH models. Journal of Forecasting, 15, 229-235. https://doi.org/10.1002/(SICI)1099-131X(199604)15:3<229::AID-FOR620>3.0.CO;2-3

Glosten, L. R., Jagannathan, R., \& Runkle, D. E. (1993). On the relation between the expected value and the volatility of the nominal excess return on stocks. The Journal of Finance, 48(5), 1779-1801. https://doi.org/10.1111/j.1540-6261.1993.tb05128.x

Grossman, S. J., \& Stiglitz, J. E. (1980). American Economic Association on the impossibility of informationally efficient markets. Source: The American Economic Review, 70(3), 393-408. Retrieved from http://www.jstor.org/sTable/1805228

Grundfest, J., \& Shoven, J. (1991). Adverse implications of a securities transactions excise tax. Journal of Accounting, Auditing \& Finance 6, 409-442. https://doi.org/10.1177/0148558X9100600402

Hakkio, C. S. (1994). Should we throw sand in the gears of financial markets? Economic Review-Federal Reserve Bank of Kansas City, 79(2), 17.

Hamid, K., Suleman, M. T., Ali Shah, S. Z., \& Akash, R. S. I. (2010). Testing the weak form of efficient market hypothesis: Empirical evidence from Asia-Pacific markets. International Research Journal of Finance and Economics, 58, 121-132. Retrieved from http://ssrn.com/abstract=1795922

Hayashida, M., \& Ono, H. (2011). Turnover tax, transaction cost and stock trading volume revisited: Investigation of the Japanese turnover tax, transaction cost and stock trading volume revisited: Investigation of The Japanese case, 3107(April).

Huang, H. H., Lin, S. H., Wang, C. P., \& Chiu, C. Y. (2014). Adjusting MV-efficient portfolio frontier bias for skewed and non-mesokurtic returns. The North American Journal of Economics and Finance, 29, 59-83. https://doi.org/10.1016/j.najef.2014.05.005

Huber, J., Kleinlercher, D., \& Kirchler, M. (2012). The impact of a financial transaction tax on stylized facts of price returns-evidence from the lab. Journal of Economic Dynamics and Control, 36(8), 1248-1266. https://doi.org/10.1016/j.jedc.2012.03.011

Hvozdyk, L., \& Rustanov, S. (2016). The effect of financial transaction tax on market liquidity and volatility: an Italian perspective. International Review of Financial Analysis, 45, 62-78. https://doi.org/10.1016/j.irfa.2016.01.018

Hyung, N., Poon, S. H., \& Granger, C. W. (2008). Chapter 9 a source of long memory in volatility. In Forecasting in the presence of structural breaks and model uncertainty. Emerald Group Publishing. 329-380. https://doi.org/10.1016/S1574-8715(07)00209-6

Kahneman, D., \& Tversky, A. (1979). Prospect theory: An analysis of decision under risk. Econometrica: Journal of the Econometric Society, 47(3), 263-291. https://doi.org/10.2307/1914185

Katusiime, L., Shamsuddin, A., \& Agbola, F. W. (2015). Foreign exchange market efficiency and profitability of trading rules: Evidence from a developing country. International Review of Economics and Finance, 35, 315-332. https://doi.org/10.1016/j.iref.2014.10.003

KPMG. (2013). Proposals to apply VAT to the financial services sector in China. Retrieved from https://www.home.kpmg.com/cn/en/home/insights/2013/12/proposals-to-apply-vat-to-the-financial-services -sector-in-china-201311.html

Lee, S. B., \& Ohk, K. Y. (1992). Stock index futures listing and structural change in time-varying volatility. Journal of Futures Markets, 12(5), 493-509. https://doi.org/10.1002/fut.3990120502

Li, H., Tang, M., Shang, W., \& Wang, S. (2013). Securities transaction tax and stock market behaviour in an agent-based financial market model. Procedia Computer Science, 18, 1764-1773. 
https://doi.org/10.1016/j.procs.2013.05.345

Ling, S., \& McAleer, M. (2002). Stationarity and the existence of moments of a family of GARCH processes. Journal of Econometrics, 106(1), 109-117. https://doi.org/10.1016/S0304-4076(01)00090-2

Liu, H. C., \& Hung, J. C. (2010). Forecasting S\&P-100 stock index volatility: The role of volatility asymmetry and distributional assumption in GARCH models. Expert Systems with Applications, 37(7), 4928-4934. https://doi.org/10.1016/j.eswa.2009.12.022

Lo, A. (2004). The adaptive market hypothesis: Market efficiency from an evolutionary perspective. The Journal of Portfolio Management, 30(5), 15-29. https://doi.org/10.3905/jpm.2004.442611

Pagan, A., \& Schwert, W. (1990). Alternative methods for conditional stock volatility. Journal of Econometrics, 45, 267-290. https://doi.org/10.1016/0304-4076(90)90101-X

Pomeranets, A. (2012). Financial transaction taxes: International experiences, issues and feasibility. Bank of Canada Review, Autumn 2012, 3-13.

Pomeranets, A., \& Weaver, D. G. (2011). Security transaction taxes and market quality. https://doi.org/10.2139/ssrn.1980185

Rahmani, M. (2016). Volatility modelling using long-memory-GARCH models, applications in S\&P/TSX composite index (Unpublished doctoral dissertation). University of Ottawa, Ontario, Canada.

Rapach, D. E., Strauss, J. K., \& Wohar, M. E. (2008). Chapter10 Forecasting stock return volatility in the presence of structural breaks. In forecasting in the presence of structural breaks and model uncertainty (pp. 381-416). Emerald Group Publishing Limited. https://doi.org/10.1016/S1574-8715(07)00210-2

Schwert, G. W., \& Seguin, P. J. (1993). Securities transaction taxes: An overview of costs, benefits and unresolved questions. Financial Analysts Journal, 49(5), 27-35. https://doi.org/10.2469/faj.v49.n5.27

Slezak, S. L. (2003). On the impossibility of weak form efficient markets. The Journal of Financial and Quantitative Analysis, 38(3), 523. https://doi.org/10.2307/4126730

Song, F., \& Zhang J. (2005). Securities transaction tax and market volatility. Economic Journal, 115, 1103-1120. https://doi.org/10.1111/j.1468-0297.2005.01034.x

Stiglitz, J. E. (1989). Financial markets and development. Oxford Review of Economic Policy, 5(4), 55-68. https://doi.org/10.1093/oxrep/5.4.55

Stitt, R. (2011). Financial supplies: Bundling and unbundling. eJournal of Tax Research 9(2), 194-219. Retrieved from http://www.austlii.edu.au/au/journals/eJITaxR/2011/11.html

Strong, N. (1992). Modelling abnormal returns: A review article, Journal of Business Finance \& Accounting, 19(4), 533-553. https://doi.org/10.1111/j.1468-5957.1992.tb00643.x

Su, Y., \& Zheng, L. (2010). The impact of securities transaction taxes on the Chinese stock market. Emerging Markets Finance and Trade, 47, 32-46. https://doi.org/10.2753/REE1540-496X4701S104

Tobin, J. (1978). A proposal for international monetary reform. Eastern Economic Journal.

West, R. R. (1975). On the difference between internal and external market efficiency. Financial Analysts Journal, 31(6). https://doi.org/10.2469/faj.v31.n6.30

Xiong, W., \& Yan, H. (2010). Heterogeneous expectations and bond markets. Review of Financial Studies, 23, 1433-1466. https://doi.org/10.1093/rfs/hhp091 


\section{Appendix A}

The Correlogram in Bursa Malaysia

\begin{tabular}{rrrrr}
\hline \hline & AC & PAC & Q-Stat & Prob* \\
\hline \hline 1 & -0.002 & -0.002 & 0.0018 & 0.966 \\
2 & -0.002 & -0.002 & 0.0038 & 0.998 \\
3 & -0.002 & -0.002 & 0.0057 & 1.000 \\
4 & -0.002 & -0.002 & 0.0077 & 1.000 \\
5 & -0.002 & -0.002 & 0.0098 & 1.000 \\
6 & -0.002 & -0.002 & 0.0118 & 1.000 \\
7 & -0.002 & -0.002 & 0.0138 & 1.000 \\
8 & -0.002 & -0.002 & 0.0159 & 1.000 \\
\hline \hline
\end{tabular}

Figure A1. The correlogram of one joint portfolio in Bursa Malaysia

\begin{tabular}{rrrrr}
\hline \hline & AC & PAC & Q-Stat & Prob* \\
\hline \hline 1 & -0.002 & -0.002 & 0.0022 & 0.963 \\
2 & -0.002 & -0.002 & 0.0043 & 0.998 \\
3 & -0.002 & -0.002 & 0.0065 & 1.000 \\
4 & -0.002 & -0.002 & 0.0087 & 1.000 \\
5 & -0.002 & -0.002 & 0.0109 & 1.000 \\
6 & -0.002 & -0.002 & 0.0131 & 1.000 \\
7 & -0.002 & -0.002 & 0.0154 & 1.000 \\
8 & -0.002 & -0.002 & 0.0176 & 1.000 \\
\hline \hline
\end{tabular}

Figure A3. The correlogram of Portfolio 2 in Bursa Malaysia

\begin{tabular}{rrrrr}
\hline \hline & AC & PAC & Q-Stat & Prob* \\
\hline \hline 1 & -0.002 & -0.002 & 0.0026 & 0.959 \\
2 & -0.002 & -0.002 & 0.0052 & 0.997 \\
3 & -0.002 & -0.002 & 0.0081 & 1.000 \\
4 & -0.002 & -0.002 & 0.0110 & 1.000 \\
5 & -0.002 & -0.002 & 0.0139 & 1.000 \\
6 & -0.002 & -0.002 & 0.0168 & 1.000 \\
7 & -0.002 & -0.002 & 0.0199 & 1.000 \\
8 & -0.002 & -0.002 & 0.0214 & 1.000 \\
\hline \hline
\end{tabular}

Figure A5. The correlogram of Portfolio 4 in Bursa Malaysia

\begin{tabular}{ccccc}
\hline \hline & AC & PAC & Q-Stat & Prob* \\
\hline \hline 1 & -0.002 & -0.002 & 0.0023 & 0.962 \\
2 & -0.002 & -0.002 & 0.0046 & 0.998 \\
3 & -0.002 & -0.002 & 0.0069 & 1.000 \\
4 & -0.002 & -0.002 & 0.0089 & 1.000 \\
5 & -0.002 & -0.002 & 0.0113 & 1.000 \\
6 & -0.002 & -0.002 & 0.0136 & 1.000 \\
7 & -0.002 & -0.002 & 0.0160 & 1.000 \\
8 & -0.002 & -0.002 & 0.0185 & 1.000 \\
\hline \hline
\end{tabular}

Figure A2. The correlogram of Portfolio 1 in Bursa Malaysia

\begin{tabular}{rrrrr}
\hline \hline & AC & PAC & Q-Stat & Prob* \\
\hline \hline 1 & -0.002 & -0.002 & 0.0022 & 0.962 \\
2 & -0.002 & -0.002 & 0.0053 & 0.997 \\
3 & -0.002 & -0.002 & 0.0075 & 1.000 \\
4 & -0.002 & -0.002 & 0.0099 & 1.000 \\
5 & -0.002 & -0.002 & 0.0130 & 1.000 \\
6 & -0.002 & -0.002 & 0.0157 & 1.000 \\
7 & -0.002 & -0.002 & 0.0186 & 1.000 \\
8 & -0.003 & -0.003 & 0.0219 & 1.000 \\
\hline \hline
\end{tabular}

Figure A4. The correlogram of Portfolio 3 in Bursa Malaysia

\begin{tabular}{rrrrr}
\hline \hline & AC & PAC & Q-Stat & Prob* \\
\hline \hline 1 & -0.010 & -0.010 & 0.0509 & 0.821 \\
2 & -0.007 & -0.007 & 0.0779 & 0.962 \\
3 & -0.014 & -0.014 & 0.1790 & 0.981 \\
4 & -0.011 & -0.012 & 0.2475 & 0.993 \\
5 & -0.016 & -0.017 & 0.3867 & 0.996 \\
6 & -0.015 & -0.016 & 0.5057 & 0.998 \\
7 & -0.000 & -0.001 & 0.5057 & 0.999 \\
8 & 0.010 & 0.009 & 0.5575 & 1.000 \\
\hline \hline
\end{tabular}

Figure A6. The correlogram of Portfolio 5 in Bursa Malaysia 


\begin{tabular}{rrrrr}
\hline \hline & AC & PAC & Q-Stat & Prob* \\
\hline \hline 1 & -0.003 & -0.003 & 0.0034 & 0.953 \\
2 & -0.002 & -0.002 & 0.0052 & 0.997 \\
3 & -0.003 & -0.003 & 0.0091 & 1.000 \\
4 & -0.003 & -0.003 & 0.0129 & 1.000 \\
5 & -0.003 & -0.003 & 0.0170 & 1.000 \\
6 & -0.003 & -0.003 & 0.0211 & 1.000 \\
7 & -0.002 & -0.002 & 0.0233 & 1.000 \\
8 & -0.002 & -0.003 & 0.0265 & 1.000 \\
\hline \hline
\end{tabular}

Figure A7. The correlogram of Portfolio 6 in Bursa Malaysia

\begin{tabular}{rrrrr}
\hline \hline & AC & PAC & Q-Stat & Prob* \\
\hline \hline 1 & -0.002 & -0.002 & 0.0023 & 0.962 \\
2 & -0.002 & -0.002 & 0.0040 & 0.998 \\
3 & -0.002 & -0.002 & 0.0069 & 1.000 \\
4 & -0.001 & -0.001 & 0.0080 & 1.000 \\
5 & -0.003 & -0.003 & 0.0118 & 1.000 \\
6 & -0.003 & -0.003 & 0.0156 & 1.000 \\
7 & -0.003 & -0.003 & 0.0195 & 1.000 \\
8 & -0.002 & -0.002 & 0.0225 & 1.000 \\
\hline \hline
\end{tabular}

Figure A9. The correlogram of Portfolio 8 in Bursa Malaysia

\begin{tabular}{ccccc}
\hline \hline & AC & PAC & Q-Stat & Prob* \\
\hline \hline 1 & -0.002 & -0.002 & 0.0019 & 0.966 \\
2 & -0.002 & -0.002 & 0.0038 & 0.998 \\
3 & -0.002 & -0.002 & 0.0058 & 1.000 \\
4 & -0.002 & -0.002 & 0.0078 & 1.000 \\
5 & -0.002 & -0.002 & 0.0098 & 1.000 \\
6 & -0.002 & -0.002 & 0.0118 & 1.000 \\
7 & -0.002 & -0.002 & 0.0138 & 1.000 \\
8 & -0.002 & -0.002 & 0.0158 & 1.000 \\
\hline \hline
\end{tabular}

Figure A11. The correlogram of Portfolio 10 in Bursa Malaysia

\begin{tabular}{ccccc}
\hline \hline & AC & PAC & Q-Stat & Prob* $^{*}$ \\
\hline \hline 1 & -0.002 & -0.002 & 0.0026 & 0.959 \\
2 & -0.002 & -0.002 & 0.0051 & 0.997 \\
3 & -0.002 & -0.002 & 0.0077 & 1.000 \\
4 & -0.002 & -0.002 & 0.0103 & 1.000 \\
5 & -0.002 & -0.002 & 0.0129 & 1.000 \\
6 & -0.002 & -0.002 & 0.0154 & 1.000 \\
7 & -0.002 & -0.002 & 0.0180 & 1.000 \\
8 & -0.002 & -0.002 & 0.0207 & 1.000 \\
\hline \hline
\end{tabular}

Figure A8. The correlogram of Portfolio 7 in Bursa Malaysia

\begin{tabular}{rrrrr}
\hline \hline & AC & PAC & Q-Stat & Prob* \\
\hline \hline 1 & -0.002 & -0.002 & 0.0021 & 0.964 \\
2 & -0.002 & -0.002 & 0.0041 & 0.998 \\
3 & -0.002 & -0.002 & 0.0062 & 1.000 \\
4 & -0.002 & -0.002 & 0.0082 & 1.000 \\
5 & -0.002 & -0.002 & 0.0104 & 1.000 \\
6 & -0.002 & -0.002 & 0.0125 & 1.000 \\
7 & -0.002 & -0.002 & 0.0145 & 1.000 \\
8 & -0.002 & -0.002 & 0.0167 & 1.000 \\
\hline \hline
\end{tabular}

Figure A10. The correlogram of Portfolio 9 in Bursa Malaysia 


\section{Appendix B}

The Correlogram of Autocorrelation Function and Partial Autocorrelation Function of ASX

\begin{tabular}{ccccc}
\hline \hline & AC & PAC & Q-Stat & Prob* \\
\hline \hline 1 & 0.009 & 0.009 & 0.0454 & 0.831 \\
2 & 0.011 & 0.011 & 0.1095 & 0.947 \\
3 & -0.036 & -0.037 & 0.8085 & 0.847 \\
4 & 0.013 & 0.014 & 0.8965 & 0.925 \\
5 & -0.047 & -0.047 & 2.0677 & 0.840 \\
6 & -0.019 & -0.019 & 2.2532 & 0.895 \\
7 & 0.072 & 0.075 & 5.0180 & 0.658 \\
8 & 0.026 & 0.022 & 5.3799 & 0.716 \\
\hline
\end{tabular}

Figure B1. The correlogram of one joint portfolio in ASX

\begin{tabular}{rrrrr}
\hline \hline & AC & PAC & Q-Stat & Prob* \\
\hline \hline 1 & -0.003 & -0.003 & 0.0057 & 0.940 \\
2 & 0.004 & 0.004 & 0.0144 & 0.993 \\
3 & -0.027 & -0.027 & 0.4113 & 0.938 \\
4 & 0.036 & 0.036 & 1.1125 & 0.892 \\
5 & 0.006 & 0.007 & 1.1337 & 0.951 \\
6 & 0.014 & 0.013 & 1.2371 & 0.975 \\
7 & -0.044 & -0.042 & 2.2794 & 0.943 \\
8 & 0.008 & 0.007 & 2.3125 & 0.970 \\
\hline \hline
\end{tabular}

Figure B3. The correlogram of Portfolio 2 in ASX

\begin{tabular}{ccccc}
\hline \hline & AC & PAC & Q-Stat & Prob* \\
\hline \hline 1 & 0.035 & 0.035 & 0.6506 & 0.420 \\
2 & 0.011 & 0.009 & 0.7107 & 0.701 \\
3 & -0.027 & -0.028 & 1.1008 & 0.777 \\
4 & -0.009 & -0.007 & 1.1444 & 0.887 \\
5 & -0.014 & -0.012 & 1.2412 & 0.941 \\
6 & -0.030 & -0.029 & 1.7020 & 0.945 \\
7 & 0.041 & 0.043 & 2.6029 & 0.919 \\
8 & 0.108 & 0.105 & 8.7674 & 0.362 \\
\hline \hline
\end{tabular}

Figure B5. The correlogram of Portfolio 4 in ASX

\begin{tabular}{rrrrr}
\hline \hline & AC & PAC & Q-Stat & Prob* \\
\hline \hline 1 & -0.007 & -0.007 & 0.0227 & 0.880 \\
2 & -0.001 & -0.001 & 0.0229 & 0.989 \\
3 & -0.007 & -0.007 & 0.0457 & 0.997 \\
4 & 0.039 & 0.039 & 0.8483 & 0.932 \\
5 & -0.006 & -0.006 & 0.8675 & 0.973 \\
6 & -0.001 & -0.001 & 0.8679 & 0.990 \\
7 & -0.006 & -0.006 & 0.8873 & 0.996 \\
8 & -0.001 & -0.002 & 0.8875 & 0.999 \\
\hline \hline
\end{tabular}

Figure B2. The correlogram of Portfolio 1 in ASX

\begin{tabular}{rrrrr}
\hline \hline & AC & PAC & Q-Stat & Prob* \\
\hline \hline 1 & -0.004 & -0.004 & 0.0096 & 0.922 \\
2 & 0.011 & 0.011 & 0.0707 & 0.965 \\
3 & -0.019 & -0.019 & 0.2619 & 0.967 \\
4 & 0.026 & 0.026 & 0.6202 & 0.961 \\
5 & -0.015 & -0.015 & 0.7449 & 0.980 \\
6 & -0.008 & -0.009 & 0.7761 & 0.993 \\
7 & 0.003 & 0.004 & 0.7797 & 0.998 \\
8 & 0.085 & 0.084 & 4.6019 & 0.799 \\
\hline \hline
\end{tabular}

Figure B4. The correlogram of Portfolio 3 in ASX

\begin{tabular}{rrrrr}
\hline \hline & AC & PAC & Q-Stat & Prob* \\
\hline \hline 1 & 0.029 & 0.029 & 0.4505 & 0.502 \\
2 & 0.062 & 0.062 & 2.4935 & 0.287 \\
3 & -0.001 & -0.005 & 2.4945 & 0.476 \\
4 & 0.016 & 0.013 & 2.6344 & 0.621 \\
5 & -0.027 & -0.028 & 3.0298 & 0.695 \\
6 & 0.020 & 0.020 & 3.2371 & 0.779 \\
7 & 0.034 & 0.037 & 3.8660 & 0.795 \\
8 & 0.092 & 0.088 & 8.3333 & 0.402 \\
\hline \hline
\end{tabular}

Figure B6. The correlogram of Portfolio 5 in ASX 


\begin{tabular}{rrrrr}
\hline \hline & AC & PAC & Q-Stat & Prob* \\
\hline \hline 1 & -0.019 & -0.019 & 0.1973 & 0.657 \\
2 & 0.002 & 0.001 & 0.1987 & 0.905 \\
3 & -0.016 & -0.016 & 0.3322 & 0.954 \\
4 & 0.109 & 0.108 & 6.5653 & 0.161 \\
5 & -0.005 & -0.001 & 6.5797 & 0.254 \\
6 & -0.031 & -0.032 & 7.0811 & 0.313 \\
7 & 0.049 & 0.052 & 8.3644 & 0.302 \\
8 & 0.093 & 0.084 & 12.929 & 0.114 \\
\hline \hline
\end{tabular}

Figure B7. The correlogram of Portfolio 6 in ASX

\begin{tabular}{ccccc}
\hline \hline & AC & PAC & Q-Stat & Prob* \\
\hline \hline 1 & 0.005 & 0.005 & 0.0150 & 0.903 \\
2 & 0.008 & 0.008 & 0.0511 & 0.975 \\
3 & -0.016 & -0.016 & 0.1861 & 0.980 \\
4 & -0.006 & -0.006 & 0.2033 & 0.995 \\
5 & -0.020 & -0.019 & 0.4059 & 0.995 \\
6 & -0.030 & -0.030 & 0.8710 & 0.990 \\
7 & -0.017 & -0.016 & 1.0208 & 0.994 \\
8 & -0.022 & -0.022 & 1.2846 & 0.996 \\
\hline \hline
\end{tabular}

Figure B9. The correlogram of Portfolio 8 in ASX

\begin{tabular}{rrrrr}
\hline \hline & AC & PAC & Q-Stat & Prob* \\
\hline \hline 1 & 0.012 & 0.012 & 0.0775 & 0.781 \\
2 & 0.008 & 0.008 & 0.1083 & 0.947 \\
3 & -0.044 & -0.044 & 1.1309 & 0.770 \\
4 & 0.018 & 0.019 & 1.2990 & 0.862 \\
5 & -0.049 & -0.049 & 2.5641 & 0.767 \\
6 & -0.013 & -0.014 & 2.6493 & 0.851 \\
7 & 0.079 & 0.082 & 5.9866 & 0.541 \\
8 & 0.035 & 0.028 & 6.6333 & 0.577 \\
\hline \hline
\end{tabular}

Figure B11. The correlogram of Portfolio 10 in ASX

\begin{tabular}{rrrrr}
\hline \hline & AC & PAC & Q-Stat & Prob* \\
\hline \hline 1 & -0.009 & -0.009 & 0.0389 & 0.844 \\
2 & 0.034 & 0.034 & 0.6468 & 0.724 \\
3 & -0.015 & -0.014 & 0.7618 & 0.859 \\
4 & 0.052 & 0.051 & 2.1834 & 0.702 \\
5 & -0.015 & -0.013 & 2.3039 & 0.806 \\
6 & -0.009 & -0.012 & 2.3432 & 0.886 \\
7 & -0.005 & -0.003 & 2.3552 & 0.938 \\
8 & 0.026 & 0.024 & 2.7215 & 0.951 \\
\hline \hline
\end{tabular}

Figure B8. The correlogram of Portfolio 7 in ASX

\begin{tabular}{rrrrr}
\hline \hline & AC & PAC & Q-Stat & Prob* \\
\hline \hline 1 & -0.016 & -0.016 & 0.1294 & 0.719 \\
2 & 0.013 & 0.013 & 0.2166 & 0.897 \\
3 & -0.007 & -0.007 & 0.2418 & 0.971 \\
4 & -0.015 & -0.015 & 0.3606 & 0.986 \\
5 & -0.035 & -0.035 & 1.0034 & 0.962 \\
6 & -0.007 & -0.008 & 1.0291 & 0.984 \\
7 & 0.015 & 0.016 & 1.1552 & 0.992 \\
8 & -0.015 & -0.015 & 1.2731 & 0.996 \\
\hline \hline
\end{tabular}

Figure B10. The correlogram of Portfolio 9 in ASX

\section{Copyrights}

Copyright for this article is retained by the author(s), with first publication rights granted to the journal.

This is an open-access article distributed under the terms and conditions of the Creative Commons Attribution license (http://creativecommons.org/licenses/by/4.0/). 